\title{
Cardiac surgery, a right target for hyperoxia?
}

\author{
Julie Boisramé-Helms ${ }^{1,2}$, Peter Radermacher ${ }^{3}$ and Pierre Asfar ${ }^{4,5^{*}}$ \\ See related research by Smit et al., http://ccforum.biomedcentral.com/articles/10.1186/s13054-016-1240-6
}

\begin{abstract}
In perioperative cardiac surgery period, supra-physiological arterial oxygen partial pressures is common practice, although there is no clear evidence of any benefit. Smit et al. have shown that a "conservative" approach did not improve hemodynamics, decrease oxidative stress or myocardial tissue damage, but was not associated with major deleterious event either. Here, we outline major oxygen friend or foes properties, which may partly explain the study results, and place the clinical trial from Smit et al. in a global context.
\end{abstract}

\section{Introduction}

Targeting supra-physiological arterial oxygen partial pressures $\left(\mathrm{PaO}_{2}\right)$ during the perioperative period of cardiac surgery is common practice [1], but why? The surgical trauma per se and the ischemia-reperfusion sequence associated with cardiopulmonary bypass $(\mathrm{CPB})$ cause hyper-inflammation and excessive release of reactive oxygen species (ROS). Any alveolar, arterial, and/or tissue hypoxia also triggers hyper-inflammation, and cardiac surgery may induce an imbalance between tissue oxygen delivery $\left(\mathrm{DO}_{2}\right)$ and oxygen consumption $\left(\mathrm{VO}_{2}\right)$ due to myocardial dysfunction, vasoplegia, microcirculation alterations, hypothermia, anemia, and hypovolemia. High inspiratory oxygen concentrations $\left(\mathrm{FiO}_{2}\right)$ can theoretically counteract this problem, but so far the optimal targets for $\mathrm{PaO}_{2}$ during $\mathrm{CPB}$ and/or the immediate postoperative ICU stay remain open [1].

\footnotetext{
* Correspondence: PiAsfar@chu-angers.fr

See related research by Smit et al., http://ccforum.biomedcentral.com/ articles/10.1186/s13054-016-1240-6

${ }^{4}$ Département de Réanimation Médicale et de Médecine Hyperbare Centre Hospitalier Universitaire, Angers 49933, Cedex 9, France

${ }^{5}$ Laboratoire de Biologie Neurovasculaire et Mitochondriale Intégrée, CNRS UMR 6214-INSERM U1083, Université Angers, PRES L'UNAM, Angers, France Full list of author information is available at the end of the article
}

\section{Main text}

Recently, Smit et al. [2] investigated whether a "conservative" oxygen approach targeting a "near-physiological" $\mathrm{PaO}_{2}$ of $130-150$ and $80-100 \mathrm{mmHg}$ during CPB and in the first 12 hours of ICU stay, respectively, would improve hemodynamics, reduce oxidative stress, and attenuate myocardial damage and visceral organ dysfunction. The control group received standard care; that is, $\mathrm{PaO}_{2}$ targets were $200-220$ and $130-150 \mathrm{mmHg}$ during CPB and early ICU stay, respectively. The main results were that the "conservative" approach did not improve hemodynamics, and neither attenuated oxidative stress (assessed by the plasma isoprostane levels and the ex-vivo ROS release in polymorphonuclear leukocytes) nor myocardial tissue damage (assessed by troponin-T levels and myocardial creatinine kinase (CK-MB) activity). However, the "conservative" strategy was not associated either with major hyperlactatemia, visceral organ dysfunction (assessed by plasma creatinine levels), or hypoxic events (defined by $\mathrm{PaO}_{2}<55 \mathrm{mmHg}$ ).

Hyperoxia has "friend-and-foe" properties, both in critically ill patients in general [3] and specifically in cardiac surgery patients [1]. Perioperative hyperoxia per se can improve oxidative killing of bacteria [3], since bactericidal properties of neutrophils depend on the $\mathrm{PO}_{2}$ in the contaminated tissue. In fact, the most recent meta-analysis on this subject including nine studies comprising 5103 patients concluded that perioperative hyperoxia may reduce surgical site infection, in particular in patients undergoing colorectal surgery [4]. Nevertheless, given the negative result of the large-scale, multicenter, randomized "Supplemental Oxygen and Complications After Abdominal Surgery" (PROXI) trial, the most recent Cochrane review [5] concluded that, so far, robust evidence is lacking to recommend the use of high $\mathrm{FiO}_{2}$ during the perioperative period, and may even be responsible for adverse events. In fact, the use of perioperative hyperoxia has been cautioned by the data on the long-term follow-up (up to 3 years) of the PROXI trial: 
hyperoxia increased long-term mortality, and this was due to the subgroup of patients undergoing cancer surgery [6], who showed a reduction in cancer-free survival [7].

Perioperative hyperoxia might also allow for myocardial ischemia-preconditioning in cardiac surgery [8]. Conversely, it may exacerbate the transitory CPB-related pulmonary injury due to increased oxidative stress and aggravated systemic inflammatory response [9]. Finally, hyperoxia may also affect hemodynamics during and after cardiac surgery due to systemic vasoconstriction, decreased heart rate, and direct negative inotropic effects, overall decreasing cardiac output $[2,3]$. It is well established that hyperoxia-induced vasoconstriction is particularly pronounced in the coronary circulation [10], thus possibly increasing susceptibility to myocardial ischemia and ischemia-reperfusion-induced injury in patients with coronary artery disease (CAD) $[2,3]$. In nonhypoxemic patients, the AVOID trial [11] showed that highflow $\mathrm{O}_{2}$ therapy during ST-segment elevation myocardial infarction increased CK-MB activity, which coincided with higher Troponin-I levels $(p=0.12)$ and infarct size $(p=0.06)$. Interestingly, albeit not significantly different $(p=0.11)$, mortality at hospital discharge was 2.5 -fold higher in the normoxia group. Hyperoxia pre-treatment (as during cardiac surgery) may prolong the "window of opportunity" prior to myocardial ischemia: highflow $\mathrm{O}_{2}$ increased the time to onset of both pacinginduced and exercise-induced myocardial ischemia in CAD patients [12, 13].

What do we learn from the study by Smit et al. [2]? The "conservative" approach did not beneficially affect the parameters assessed, but had no deleterious side effects either. Signs of possible tissue hypoperfusion (i.e., lactate levels) only showed a mild increase (maximum $2 \mathrm{mmol} / \mathrm{l}$ ) independently of the group assignment, and none of the patients showed major organ dysfunction. It remains unclear whether the "conservative" approach substantially altered $\mathrm{DO}_{2}$ and/or $\mathrm{VO}_{2}$ : the cardiac index and total hemoglobin content were comparable, and the time-weighted $\mathrm{PaO}_{2}$ values (220 vs. $157 \mathrm{mmHg}, 214$ vs. $147 \mathrm{mmHg}$, and 107 vs. $90 \mathrm{mmHg}$ during CPB, aorticcross clamping, and ICU stay, respectively) suggest that there were no major differences in hemoglobin $\mathrm{O}_{2}$ saturation. Since neither glycemia nor data on insulin requirements are reported, it remains open whether there was any difference in metabolic substrate utilization: increasing $\mathrm{FiO}_{2}$ was reported to reduce $\mathrm{O}_{2}$ uptake in critically ill patients and, eventually, switch energy metabolism to preferential carbohydrate use [3]. Finally, as the authors acknowledge themselves, the systematic dexamethasone administration after induction of anesthesia may have mitigated any further effect of the different $\mathrm{O}_{2}$ strategy. Nevertheless, the results presented by Smit et al. are of major interest and clinical importance given the current practice comprising administration of high $\mathrm{FiO}_{2}$ levels and targeting supra-physiological $\mathrm{PaO}_{2}$ values in cardiac surgery. Previous studies have already suggested that more conservative $\mathrm{O}_{2}$ targets might be beneficial $[14,15]$. However, in these studies the "hyperoxic" groups had $\mathrm{PaO}_{2}$ levels of 400-500 $\mathrm{mmHg}$ during $\mathrm{CPB}$, and the "lower", socalled "normoxic" groups were titrated to $\mathrm{PaO}_{2}$ levels of $140 \mathrm{mmHg}$ [14] and 200-250 $\mathrm{mmHg}$ [15], respectively; that is, close to the targets of the hyperoxic "control" arm in the present investigation. Moreover, $\mathrm{PaO}_{2}$ strategies were only modified during $\mathrm{CPB}$, whereas Smit et al. also targeted the early ICU stay.

\section{Conclusion}

Despite some study limitations, Smit et al. have to be commended for performing an elegant clinical trial on routine procedures that had so far never undergone rigorous testing under randomized, controlled conditions. The results of their much larger "Optimal Oxygenation in the Intensive Care Unit (O2-ICU)" trial (ClinicalTrials.gov NCT02321072) comparing high-normal vs. low-normal (120 vs. $75 \mathrm{mmHg}$ ) $\mathrm{PaO}_{2}$ targets in ICU patients is therefore eagerly awaited.

\section{Abbreviations \\ CAD, coronary artery disease; $C P B$, cardiopulmonary bypass; CK-MB, myocardial creatinine kinase; $\mathrm{DO}_{2}$, oxygen delivery; $\mathrm{FiO}_{2}$, inspiratory oxygen concentrations; $\mathrm{PaO}_{2}$, arterial oxygen partial pressures; ROS, reactive oxygen species; $\mathrm{VO}_{2}$, oxygen consumption}

\section{Acknowledgements}

PR was supported by the Deutsche Forschungsgemeinschaft (CRC1149, Project B03).

\section{Authors' contributions}

All authors helped to draft the manuscript, and read and approved the final manuscript.

\section{Competing interests}

The authors declare that they have no competing interests.

\section{Author details}

'Service de Réanimation Médicale, Nouvel Hôpital Civil, Hôpitaux Universitaires de Strasbourg, Strasbourg, France. ²EA 7293, Fédération de Médecine Translationnelle de Strasbourg (FMTS), Faculté de médecine,

Université de Strasbourg, Strasbourg, France. ${ }^{3}$ Institut für Anästhesiologische Pathophysiologie und Verfahrensentwicklung, Universitätsklinikum Ulm, Helmholtzstrasse 8/1, 89081 Ulm, Germany. ${ }^{4}$ Département de Réanimation Médicale et de Médecine Hyperbare Centre Hospitalier Universitaire, Angers 49933, Cedex 9, France. ${ }^{5}$ Laboratoire de Biologie Neurovasculaire et Mitochondriale Intégrée, CNRS UMR 6214-INSERM U1083, Université Angers, PRES L'UNAM, Angers, France.

Published online: 16 June 2016

\section{References}

1. Spoelstra-de Man AM, Smit B, Oudemans-van Straaten HM, Smulders YM. Cardiovascular effects of hyperoxia during and after cardiac surgery. Anaesthesia. 2015;70:1307-19.

2. Smit B, Smulders YM, de Waard MC, Boer C, Vonk AB, Veerhoek D, et al. Moderate hyperoxic versus near-physiological oxygen targets during and after coronary artery bypass surgery: a randomised controlled trial. Crit Care. 2016;20:55. 
3. Hafner S, Beloncle F, Koch A, Radermacher P, Asfar P. Hyperoxia in intensive care, emergency, and peri-operative medicine: Dr. Jekyl or Mr. Hyde? A 2015 update. Ann Int Care. 2015;5:42.

4. Hovaguimian F, Lysakowski C, Elia N, Tramer MR. Effect of intraoperative high inspired oxygen fraction on surgical site infection, postoperative nausea and vomiting, and pulmonary function: systematic review and meta-analysis of randomized controlled trials. Anesthesiology. 2013;119:303-16.

5. Wetterslev J, Meyhoff CS, Jorgensen LN, Gluud C, Lindschou J, Rasmussen LS. The effects of high perioperative inspiratory oxygen fraction for adult surgical patients. Cochrane Database Syst Rev. 2015;6:CD008884.

6. Meyhoff CS, Jorgensen LN, Wetterslev J, Christensen KB, Rasmussen LS, Group PT. Increased long-term mortality after a high perioperative inspiratory oxygen fraction during abdominal surgery: follow-up of a randomized clinical trial. Anesth Analg. 2012;115:849-54.

7. Meyhoff CS, Jorgensen LN, Wetterslev J, Siersma VD, Rasmussen LS, Group PT. Risk of new or recurrent cancer after a high perioperative inspiratory oxygen fraction during abdominal surgery. Br J Anaesth. 2014;113 Suppl 1:i74-81.

8. Karu I, Tahepold P, Ruusalepp A, Reimann E, Koks S, Starkopf J. Exposure to sixty minutes of hyperoxia upregulates myocardial humanins in patients with coronary artery disease — a pilot study. J Physiol Pharmacol. 2015;66:899-906.

9. Pizov R, Weiss YG, Oppenheim-Eden A, Glickman H, Goodman S, Koganov Y, et al. High oxygen concentration exacerbates cardiopulmonary bypassinduced lung injury. J Cardiothor Vasc Anesth. 2000;14:519-23.

10. Ganz W, Donoso R, Marcus H, Swan HJ. Coronary hemodynamics and myocardial oxygen metabolism during oxygen breathing in patients with and without coronary artery disease. Circulation. 1972:45:763-8.

11. Stub D, Smith K, Bernard S, Nehme Z, Stephenson M, Bray JE, et al. Air versus oxygen in ST-segment-elevation myocardial infarction. Circulation. 2015;131:2143-50.

12. Horvat M, Yoshida S, Prakash R, Marcus HS, Swan HJ, Ganz W. Effect of oxygen breathing on pacing-induced angina pectoris and other manifestations of coronary insufficiency. Circulation. 1972;45:837-44.

13. Ranchord AM, Argyle R, Beynon R, Perrin K, Sharma V, Weatherall M, et al. High-concentration versus titrated oxygen therapy in ST-elevation myocardial infarction: a pilot randomized controlled trial. Am Heart J. 2012:163:168-75.

14. Innken K, Winkler A, Schlensak C, Sarai K, Neidhart G, Unkelbach U, et al. Normoxic cardiopulmonary bypass reduces oxidative myocardial damage and nitric oxide during cardiac operations in the adult. J Thorac Cardiovasc Surg. 1998;116:327-34.

15. Inoue T, Ku K, Kaneda T, Zang Z, Otaki M, Oku H. Cardioprotective effects of lowering oxygen tension after aortic unclamping on cardiopulmonary bypass during coronary artery bypass grafting. Circulation J. 2002;66:718-22. 